\title{
A New Tri-Generation System: Thermodynamical Analysis of a Micro Compressed Air Energy Storage
}

\author{
Andrea Vallati ${ }^{1}$, Stefano Grignaffini ${ }^{1}$, Alessandro Quintino ${ }^{1}$, Marco Romagna ${ }^{1}$ and Luca Mauri ${ }^{2}$ \\ 1. DIAEE Department of Astronautical, Electrical and Energetical Engineering- “Sapienza” University of Rome, Via Eudossiana 18, \\ 00184 Rome, Italy \\ 2. Department of Mechanical Engineering, University of Roma TRE, Via della Vasca Navale 79, 00146 Rome, Italy
}

Received: June 22, 2016 / Accepted: July 07, 2016 / Published: November 30, 2016.

\begin{abstract}
There is a growing interest in the electrical energy storage system, especially for matching intermittent sources of renewable energy with customers' demand. Furthermore, it is possible, with these system, to level the absorption peak of the electric network (peak shaving) and the advantage of separating the production phase from the exertion phase (time shift). CAES (compressed air energy storage systems) are one of the most promising technologies of this field, because they are characterized by a high reliability, low environmental impact and a remarkable energy density. The main disadvantage of big systems is that they depend on geological formations which are necessary to the storage. The micro-CAES system, with a rigid storage vessel, guarantees a high portability of the system and a higher adaptability even with distributed or stand-alone energy productions. This article carries out a thermodynamical

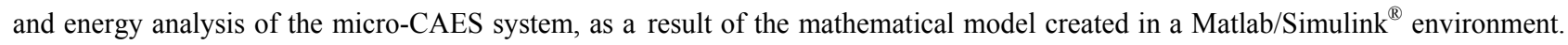
New ideas will be discussed, as the one concerning the quasi-isothermal compression/expansion, through the exertion of a biphasic mixture, that will increase the total system efficiency and enable a combined production of electric, thermal and refrigeration energies. The exergy analysis of the results provided by the simulation of the model reports that more than one third of the exergy input to the system is lost. This is something promising for the development of an experimental device.
\end{abstract}

Key words: CAES, thermodynamic analysis, exergy analysis, quasi-isothermal compression/expansion.

\section{Nomenclature}

$T_{0} \quad$ Input temperature at the compressor $\left({ }^{\circ} \mathrm{C}\right)$

$T_{c} \quad$ Output temperature at the compressor $\left({ }^{\circ} \mathrm{C}\right)$

$Q_{h c} \quad$ Maximum amount of heat extractable during the

Qhe compression phase $(\mathrm{kJ} / \mathrm{kg})$

$Q_{c o} \quad$ Total heat subtracted during the expansion phase

Qce $\quad(\mathrm{kJ} / \mathrm{kg})$

$\beta \quad$ Pressure ratio

$E_{C} \quad$ Absorbed energy by the system (compressor)

$E_{C} \quad(\mathrm{kWh})$

$E_{E} \quad$ The energy transferred from the system (turbine)

$(\mathrm{kWh})$

$\eta_{h} \quad$ Efficiency of heating side (\%)

$\eta_{c} \quad$ Efficiency of cooling side (\%)

$E_{e l, h} \quad$ Heating energy in the thermal storage

$E_{e l, c} \quad$ Cooling energy in the thermal storage

$E x_{y l, c} \quad$ Exergy present in the hot liquid absorbed during

Corresponding author: Andrea Vallati, assistant professor, research fields: energy saving, buildings performance, heat exchange. the compression phase $(\mathrm{kJ} / \mathrm{kg})$

Exergy present in the cold liquid, due to the cooling expansion phase $(\mathrm{kJ} / \mathrm{kg})$

Exergy absorbed by the liquid during the thermal exchange with the air after the compression $(\mathrm{kJ} / \mathrm{kg})$ Exergy present in the liquid during the thermal exchange with the air after the expansion $(\mathrm{kJ} / \mathrm{kg})$ Thermodynamical efficiency of the CAES, only mechanical power $(\%)$

Polygenerative efficiency of the CAES,

$\begin{array}{ll}\eta_{p o l, C A E S} & \text { mechanical power and heat }(\%) \\ \eta_{e x, C A E S} & \text { Total exergy efficiency }(\%)\end{array}$

$L_{e} \quad$ Specific compression work $(\mathrm{kJ} / \mathrm{kg})$

$L_{c} \quad$ Specific expansion work $(\mathrm{kJ} / \mathrm{kg})$

$L_{e x, c} \quad$ Exergy destroyed during the compression phase

$\quad(\mathrm{kJ} / \mathrm{kg})$

$L_{e x, e} \quad$ Exergy destroyed during the expansion phase $(\mathrm{kJ} / \mathrm{kg})$

\section{Introduction}

The global demand for energy is rising fast and this fact leads to a rapid consumption of a traditional fossil 
fuel. To address issues related to fossil fuel consumption, renewable energy resources, are quickly developing in recent years. However, the intermittency of renewable power sources, such as wind and photovoltaic, presents a great obstacle to their extensive penetration into the power grid. In order to enhance the utilization of the renewable energy sources for power generation, energy storage solutions are indispensable. In fact, the interest in electrical energy storage systems is due to their ability in decoupling the electric power generation phase and the consumption phase $[1,2]$.

To solve this problem, different energy storage technologies such as pumped hydro, compressed-air, battery, flywheel and TES (thermal energy storage) systems are explored and developed. Compared to pumped hydro energy storage, CAES (compressed air energy storage) with artificial vessel is less dependent on local topography; compared to battery, flywheel, capacitor, supercapacitor and superconducting magnetic, discharge time of CAES is longer, discharge loss is smaller and power rating is bigger; compared to thermal energy storage, available energy efficiency is higher because available energy of heat is very small [3]. This kind of technology is considered as a most promising storage option due to a very high reliability, environmental friendliness, economic feasibility, and safe and simple operation $[4,5]$.

Historically, CAES has been deployed for grid management applications such as load shaving, load following, load shifting and regulation. Thus, this technology has been applied for large-size power plants.

Recently, the attention seems to be also devoted to small-size and/or innovative applications as confirmed by the technical literatures [6-12].

Baquari and Vahidi [6] proposed a case study of a S-CAES (small-compressed air energy storage) system in Iran cities. The S-CAES system is operated in low pressure (not more than 10 bars), so it can be used everywhere. It consists of a compressor for changing the air into the reservoir and a turbo-expander. An induction motor/generator is connected through clutches to the compressor and the turbine. During consumption periods, the CAES system is operated in discharging mode and the compressed air is released from the reservoir to the expander in order to provide the needed power. They calculated the total efficiency of the system as function of the pressure ratio (pressure of the initial state and final state) and showed that, in the range from 3 to 9 , the efficiency was not noticeable but after 10 it was high (0.4-0.6). Kim and Favrat [7] performed energy and exergy analyses of different types of micro-CAES systems and proposed some innovative ideas for achieving high efficiencies from these systems. They considered the possibility of using both the dissipated heat of compression for heating load and the compressed air for the power generation and the cooling load. The authors analyzed eight CAES system configurations in which the storage pressure was fixed at 50 bar. These configurations are characterized by: (a) quasi-isothermal or adiabatic compressions and expansions; (b) one or two compression and expansion stages; (c) with or without fuel addition for heating the compressed air before its expansion. The results of their study highlighted that a micro-CAES system, especially with quasi-isothermal compression and expansion processes, is a very effective system for distributed power networks, because it can be a combination of energy storage, generation, air-cycle heating and cooling system and it has a good efficiency (about 60\%). A further innovation proposed by the authors regards charging and discharging processes of a high-pressure vessel where the pressure ratios are changing. They considered a new storage system that combines a constant-pressure air storage and a hydraulic energy storage; as matter of fact, the system produces the required large pressure difference by means of a water column. Alami [12] presented an experimental evaluation of two compact energy storage devices directed towards wind energy storage applications. The 
CAES system, that was considered as isothermal because maximum pressure is not exceed 3 bar and has an overall efficiency that is function of the cylinder pressure with its maximum value of $84.8 \%$. The maximum theoretical efficiency for the buoyancy work system is found to be around $36 \%$. The systems considered in the analysis were compact in size but the results obtained in terms of performance parameters, such as efficiency and electrical output, can be generalized as a storage option for real offshore wind farms. A new CAES refrigeration system proposed by Wang et al. [13] consists of a gas refrigeration cycle and a vapor compression refrigeration cycle. Based on the micro-CAES and thermal energy storage, the tri-generation system suggested by $\mathrm{Li}$ et al. [10] can release energy via three means: electrical, heating and cooling power. The hybrid wind diesel CAES system for remote areas proposed by Ibrahim et al. $[14,15]$ can heighten diesel power output, increase engine lifetime and efficiency and, at the same time, reduce fuel consumption and greenhouse gas emissions. In Italy, Jannelli [16] proposed a small scale adiabatic CAES, integrated with a thermal energy storage unit with inter-cooling compression and inter-heating expansion. This configuration, with a compressor size equal to 3.7 $\mathrm{kW}$ provides a storage system efficiency equal to $57 \%$.

It should be noted that the discharged air temperature of all CAES systems presented in those references is high, therefore a considerable amount of thermal energy is lost. In order to solve this problem, an innovative tri-generation CAES system is proposed in this paper. Heat produced in compression process is stored and used as heating energy. Compressed air directly expands in the turbine motor to do work and to produce cooling energy. Unlike other CAES systems, a preheating process is not required in the proposed CAES and the low-temperature discharged air can be used as cooling energy instead of abandoned. Therefore, the proposed system can simultaneously provide mechanical energy, heating and cooling energy. In Ref. [17] the authors show that, in a tri-generation
CAES system, using the air as cooling power, can improve the total energy efficiency of the system by $20-30 \%$.

In order to research the system performance of the proposed tri-generation CAES system, the corresponding thermodynamic analysis is carried out and the corresponding theoretical additional efficiency is also calculated in this paper.

\section{System Description}

Fig.1 shows the schematic configuration of the micro CAES proposed in this paper. It is a high-pressure compressed air storage system (50 bar); it is a small-scale $(3 \mathrm{~kW})$ with quasi-isothermal expansion and compression and a constant volume storage $\left(1 \mathrm{~m}^{3}\right)$.

As can be seen in Fig. 1 the CAES, separate the compression and expansion cycle into two different processes, allowing the energy storage as compressed air. The execution time of the two phases, charge-discharge, is important because it must consider the load and supply requirements of energy. During low demand periods, the compressed air is stored in a vessel. To extract the energy stored, the compressed air is taken from the storage tank by means of some valves regulating the output flow and is expanded in the turbine by activating the electrical generator which restores part of the electric energy previously absorbed. Moreover, the choice of quasi-isothermal compression/expansion was due to both the thermodynamic advantages and a possible thermal recovery in these two main phases. The first aspect: a quasi-isothermal compression/expansion (Ericsson cycle), allows a higher efficiency than an adiabatic process (Brayton cycle). This is due to the fact that the result is a lower work during the compression phase and a higher work during the expansion phase. The second aspect: the heat recovered from compression phase can supply a thermal load, while during the expansion phase, without preheating the gas (on the other hand it is something that happens in conventional 


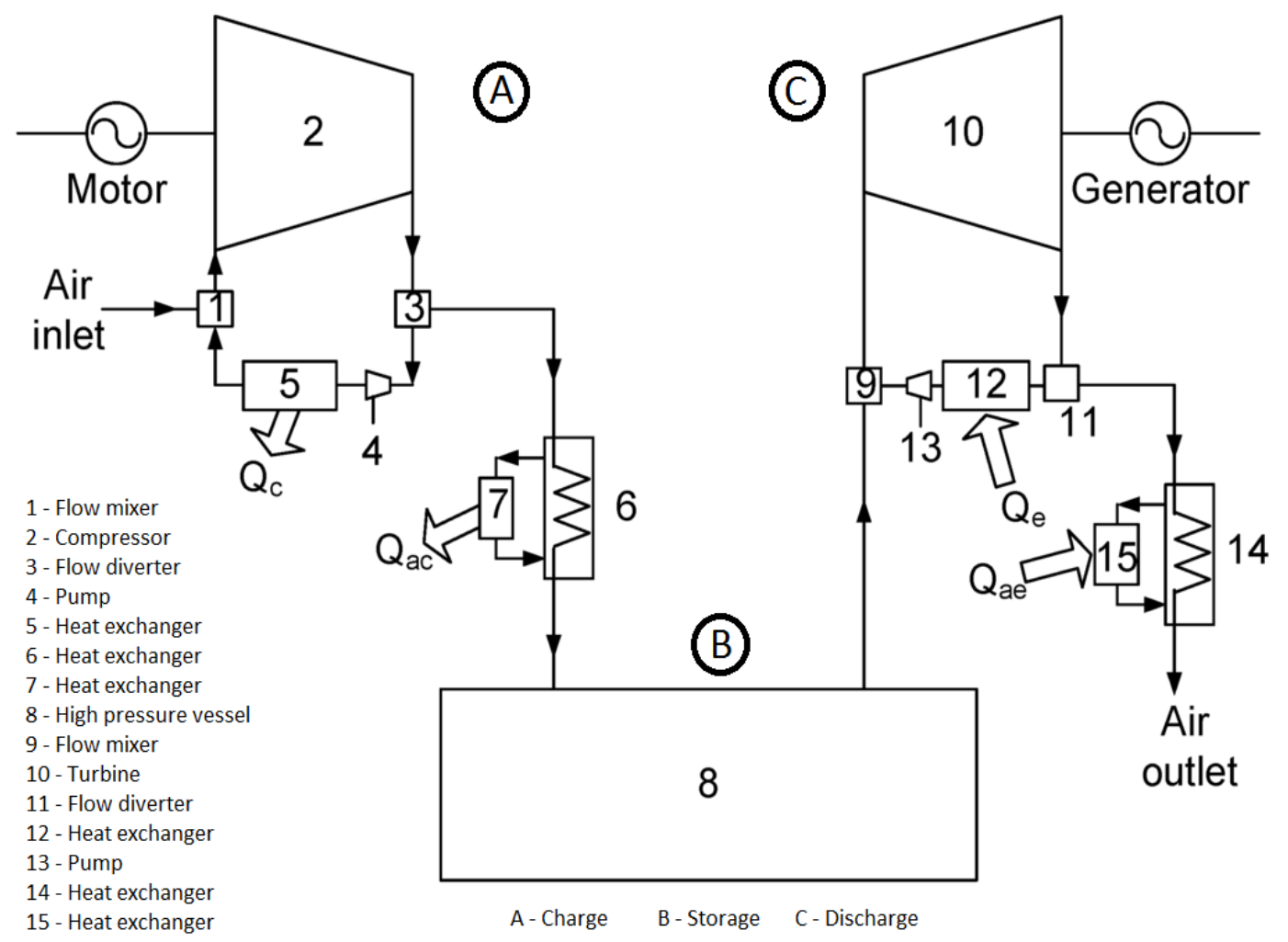

Fig. 1 Layout of proposed micro-CAES system.

CAES or adiabatic systems), the output fluid can be used for the cooling process of an environment, thus generating a tri-generation system.

\section{Methodology}

We propose a new system that combines two energy conversion processes: storing electricity by generating compressed air and driving the turbine motor to generate mechanical energy and low temperature discharged air. Therefore it is necessary to establish a thermodynamic model and to analyze the energy efficiency of the proposed system. To simplify the theoretical analysis, the following assumptions are used: (a) air can be regarded as ideal gas and meets ideal gas state equation, (b) incompressible, nonvolatile liquid, (c) no pressure drops, (d) all components operate adiabatically (except the heat exchangers), (e) perfect separation, (f) perfect mixing, (g) combined liquid and gas flows are in thermal equilibrium.

\subsection{Quasi-Isothermal Compression/Expansion}

The analysis of the compression/expansion of a gas containing the liquid, is based on the model proposed by Hugenroth $[18,19]$. This model is used by Bell et al. on the compression/expansion "flooded" in a scroll-type volumetric machine [20,21]. To obtain this kind of compression/expansion a big amount of water finely atomized is mixed with the air and inserted into the machine. The thermal energy recovered during both phases can be sent to a storage, necessary to supply a thermal/cooling load [7]. An analytical compressor model was developed by examining the behavior of an ideal gas that is in contact with a liquid and defining for properties of a pseudo-gas that characterizes the mixture. Using these properties, standard thermodynamic relations can be used to determine the compression power and temperature change for the compressed gas. Then the compression/expansion process of an ideal gas, with a specific heat ratio of $k$ 
$\left(c_{p} / c_{v}\right)$ and in a thermal balance with a liquid, with a constant specific heat $\left(c_{l}\right)$ and a behavior similar to the gas, can be examined through a ratio between specific heats concerning the mixture, whose value is $k^{*}$.

$$
k^{*}=\frac{c_{p, g}{ }^{*}}{c_{v, g}{ }^{*}}=\frac{m_{g} c_{p, g}+m_{l} c_{l}}{m_{g} c_{v, g}+m_{l} c_{l}}
$$

The compression process can be considered as isentropic where $k$ will be substituted with $k^{*}$. But first here is the list of the hypothesis adopted: (a) the compression process was assumed to occur in a stationary condition, (b) potential and kinetic energy are minimum and chemical or nuclear reactions are absent, (c) the compressor and expander isentropic efficiency is $80 \%$, (d) the electrical generator and motor efficiency is $90 \%$, (e) the process is divided into two stages with the same pressure ratio for a $\beta_{T O T}=50$. A higher gas temperature, caused by the process, can be defined through the typical isentropic relation as showed in the following expression:

$$
\frac{T_{o}}{T_{c}}=\beta^{\frac{k^{*}-1}{k^{*}}}
$$

\subsection{Compressed Air Storage}

This stage is very important because it determines the end pressure of the compression phase once the storage is full. Furthermore, in the discharge step, according to the load requirements, it is possible to adjust the output flow and consequently the discharge time. The selected volume is $1 \mathrm{~m}^{3}$ with a storage pressure of 50 bar. These data represent a good compromise between energy density, cost, efficiency of the system and all the problems related to the size [20].

\subsection{Thermal Storage}

The thermal storage system used for the model is sensible heat type. The thermodynamic and energetic relations regulating heating and cooling processes are basically the same. The only difference can be found in the heat transfer liquid. For the hot-side (compression) is simply water, whereas for the cold-side it will be mixed to an anti-freeze substance that tends to decrease the freezing point like an aqueous solution at $56 \%$ of 1-, 2-ethanol which presents a freezing point of $-50{ }^{\circ} \mathrm{C}$ [22]. The thermal energy stored is the result of the algebraic addition of the contributions of positive energy in input and negative one in output. Assuming that the latter is ignored, there is no connected load and the tank is considered adiabatic $(\mathrm{dQ}=0)$. The last hypothesis considered the energy amount stored in a short time period and then directly used. Then, for the micro CAES system proposed in this paper, the following parameters are to be considered: during the compression and heat exchange process, air at pressure $p_{0}$ and temperature $T_{0}$ from ambient conditions is compressed by the air compressor. After this process electrical energy is converted into the potential energy and thermal energy. After the heat exchange process, hot water at temperature $T_{w}$ is stored in the TES, and the compressed air at temperature $T_{c}$ and pressure $p_{c}$ is stored in the vessel for future use. When there is energy demand, compressed air with potential energy is released from the vessel. During the expansion process of compressed air in the turbine, mechanical energy can be generated. Simultaneously, low-temperature discharged air at temperature $T_{e}$ and pressure $p_{e}$ is also generated. The discharged air can be completely used as cooling power.

\section{Energy and Exergy Analysis}

In the studied system $E_{c}$ is the energy absorbed by the system during the charging phase.

During the discharging phase the energy pressure is transformed into electrical energy, the energy transferred from the system is $E_{e}$. Then the electric efficiency of the total storage will be expressed as follows:

$$
\eta_{I, C A E S}=\frac{E_{e}^{-}}{E_{c}^{+}}
$$

It is possible to use the heat dissipated during the 
compression phase to supply a thermal load and use the cold gas in output from the expander, because no fuel is used to meet cooling demand.

The system performances concerning this thermal aspects (compressor) can be stressed as follows:

$$
\eta_{h}=\frac{Q_{h c}}{E_{c}^{+}}
$$

The performances concerning the cooling process (turbine) are:

$$
\eta_{c}=\frac{Q_{c e}}{E_{c}^{+}}
$$

Finally it can be expressed a polygenerative efficiency that takes into consideration the useful effect determined by the thermal storages added to the one caused by the energy transferred from the turbine. Such condition can be obtained by comparing the energy present in thermal storages with the electric energy required by a heat pump to produce them, as the following relations [23]:

$$
\eta_{p o l, C A E S}=\frac{E_{e}^{-}+E_{e l, H}+E_{e l, C}}{E_{c}^{+}}
$$

Using the first and second law of thermodynamics is possible to make a comparison between the different forms of energy and identify the conditions of more efficient use of energy sources. The global exergy efficiency can be estimated by calculating the ratio between the exergy transferred and the one absorbed by the system. The one in input only concerns the energy absorbed during the compression phase $\left(E_{c}{ }^{+}\right)$. The one transferred from the system is the total of the one transferred from the turbine $\left(E_{e}^{-}\right)$and the one present in the hot liquid absorbed during the compression phase $\left(E x_{y l, c}\right)$ plus the one absorbed by the liquid during the thermal exchange with the air after the compression $\left(E x_{y l, a c}{ }^{-}\right)$. Moreover it must be added the exergy present in the cold liquid, due to the cooling during the expansion $\left(E x_{y l,}{ }^{-}\right)$and the one present in the liquid during the thermal exchange with the air after the expansion $\left(E x_{y l a}{ }^{-}\right)$. The total exergy efficiency of the system, while taking into consideration what was previously said, can be expressed as follows:

$$
\eta_{e x, C A E S}=\frac{E_{e}^{-}+E x_{y l, c}^{-}+E x_{y l, a c}^{-}+E x_{y l, e}^{-}+E x_{y l, a e}^{-}}{E_{c}^{+}}
$$

\section{Model Validation}

It is very important to validate the mathematical model to ensure the adequacy and validity of the obtained results. The system at issue here is new and therefore the validation process was conducted by comparing it with other similar works, that are, to be more specific, the publications of Kim et al. [7, 23, 24]. Both systems present the same configuration and are two tri-generation micro-CAES systems where the processes of compression and expansion are in quasi-isothermal condition. Table 1 shows some important energetic parameters, useful to validate our model. In particular the electric energy absorbed by the compressor $\left(E_{c}^{+}\right)$and the one transferred from the turbine $\left(E_{e}^{-}\right)$, whose ratio determines the system efficiency $\left(\eta_{I, C A E S}\right)$.

Table 2 shows the compression ratio $(\beta)$, the final compression temperature $\left(T_{c}\right)$ and the one of the expansion $\left(T_{e}\right)$, the specific compression work $\left(L_{c}\right)$ and the one of the turbine $\left(L_{e}\right)$.

There is good agreement between the results of our model and the Kim's model results. The different output temperatures which characterize the two phases are determined by a different relationship between the liquid and the gas of the mixture. What has been said earlier causes small differences between the values of the specific works, thus affecting the efficiency of the system.

The differences that can be noticed among the values concerning the thermal energy transferred (compression)

Table 1 Comparison of the energy indexes of the systems.

\begin{tabular}{lll}
\hline & Our model results & Kim's results \\
\hline$\eta_{I, C A E S}(\%)$ & $52 \%$ & $57 \%$ \\
$Q_{h c}(\mathrm{~kJ} / \mathrm{kg})$ & 375.25 & 340 \\
$\eta_{h}(\%)$ & $75 \%$ & $80 \%$ \\
$Q_{c e}(\mathrm{~kJ} / \mathrm{kg})$ & 326.88 & 314 \\
$\eta_{c}(\%)$ & $72 \%$ & $74 \%$ \\
$E_{e}^{-}(\mathrm{kWh})$ & 2.81 & 2.85 \\
$E_{c}^{+}(\mathrm{kWh})$ & 5.34 & 5 \\
\hline
\end{tabular}


Table 2 Comparison between specific works and maximum heat exchanged during both phases.

\begin{tabular}{lll}
\hline & Our model results & Kim's results \\
\hline$\beta$ & $50(7.1 \& 7.1)$ & $50(7.1 \& 7.1)$ \\
$T_{c}\left({ }^{\circ} \mathrm{C}\right)$ & 90 & 80 \\
$L_{c}(\mathrm{~kJ} / \mathrm{kg})$ & 454 & 425 \\
$T_{e}\left({ }^{\circ} \mathrm{C}\right)$ & -8 & -6 \\
$L_{e}(\mathrm{~kJ} / \mathrm{kg})$ & 236.08 & 242.25 \\
\hline
\end{tabular}

Table 3 Comparison of the specific exergy results.

\begin{tabular}{lll}
\hline & Our model results & Kim's results \\
\hline$E x_{c}^{+} \quad(\mathrm{kJ} / \mathrm{kg})$ & 454 & 425 \\
$L_{e x, c} \quad(\mathrm{~kJ} / \mathrm{kg})$ & 90.80 & 85 \\
$E x_{e}^{-} \quad(\mathrm{kJ} / \mathrm{kg})$ & 236.93 & 267 \\
$L_{e x, e} \quad(\mathrm{~kJ} / \mathrm{kg})$ & 53.24 & 60 \\
$E x_{y l, c}^{-}(\mathrm{kJ} / \mathrm{kg})$ & 19.52 & 22 \\
$E x_{y l, a c}^{-} \quad(\mathrm{kJ} / \mathrm{kg})$ & 9.76 & 11 \\
$E x_{y l, e}^{-} \quad(\mathrm{kJ} / \mathrm{kg})$ & 10.65 & 12 \\
$E x_{y l, a e}^{-} \quad(\mathrm{kJ} / \mathrm{kg})$ & 1.77 & 2 \\
$\eta_{e x, C A E S} \quad(\%)$ & $62 \%$ & $68 \%$ \\
\hline
\end{tabular}

and subtracted (expansion) from the liquid phase of the mixture are determined by the model comparison which imposes the efficiency values of thermal exchange ( $80 \%$ compression $74 \%$ expansion) [21]; instead, in this study, they are provided by the mathematical model of the system.

The final steps of the validation process are the comparison concerning the exergy analysis that determines the quality of the energy, performed by comparing the energy conservation and its change over time thus causing the degradation of the energy, due to the irreversibility of the process. Table 3 shows the exergy balance of the system with an efficiency exergetic evaluation $\left(\eta_{\text {ex, }}\right.$ CAES $)$.

\section{Results and Discussion}

The mathematical model implemented was used to assess the energy features of a $3 \mathrm{~kW}$ CAES, with storage capacity of $1 \mathrm{~m}^{3}$ and a pressure of 50 bar.

Figs. 2a-2c show the main characteristics of the system which have been already reported in the previous tables. As it can be seen the performance increases by $20 \%$ when considering not only the mechanical power efficiency but the combined heat and mechanical power efficiency.

This result is in line with those found by Liu and Wang [17] and they strongly suggest how quasi-isothermal compression and expansion processes are very helpful to minimize exergy loss in heat transfer process and how they result effective for a micro CAES system installed to meet a residential heating and cooling demand.

To understand how this system could be inserted into an integrated plant of a residential configuration, the charge and discharge times of the system were evaluated too.

The system was examined in an operating period of a whole day during which a charge/discharge cycle was performed in $1.88 \mathrm{~h}$ for the storage phase (Fig. 3) and $1.08 \mathrm{~h}$ to perform the full discharge of the system (Fig. 4).

Moreover the system absorbed $5.34 \mathrm{kWh}$ to execute the charge phase; it is important to underline that the energy required by this process was thought it would be provided almost entirely by some kind of renewable energy source, thus actually creating a tri-generation system. The trend of temperature in the thermal storage is shown in Fig. 5.

During the discharge phase there was a release of $2.81 \mathrm{kWh}$ for a round-trip efficiency of $52 \%$. The thermal storage determined by the heat subtracted during the compression phase was of $1.89 \mathrm{kWh}$ while the refrigeration energy stored during the expansion phase was of $1.39 \mathrm{kWh}$.

While examining these two aspects representing the peculiarity of the system, if compared to other types of storage such as batteries, it can be noticed how the power efficiency reported a net value of $70 \%$.

However compression air systems can offer some advantages respect to conventional batteries which require precious and expensive materials (characterized by a short service life), an efficiency affected by the operating conditions and high dissipation costs. 


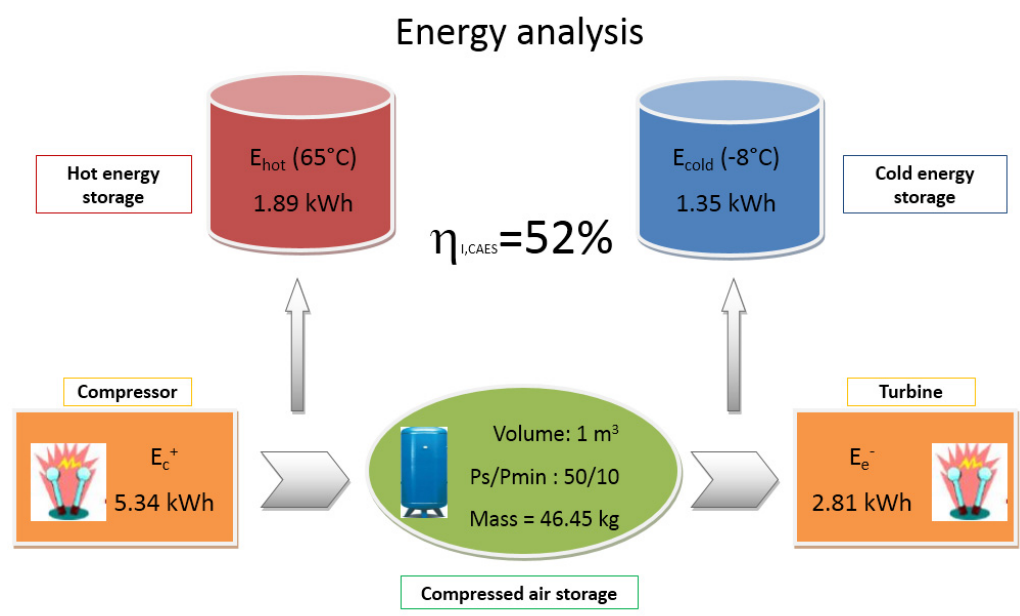

(a) Energy results

Exergy analysis

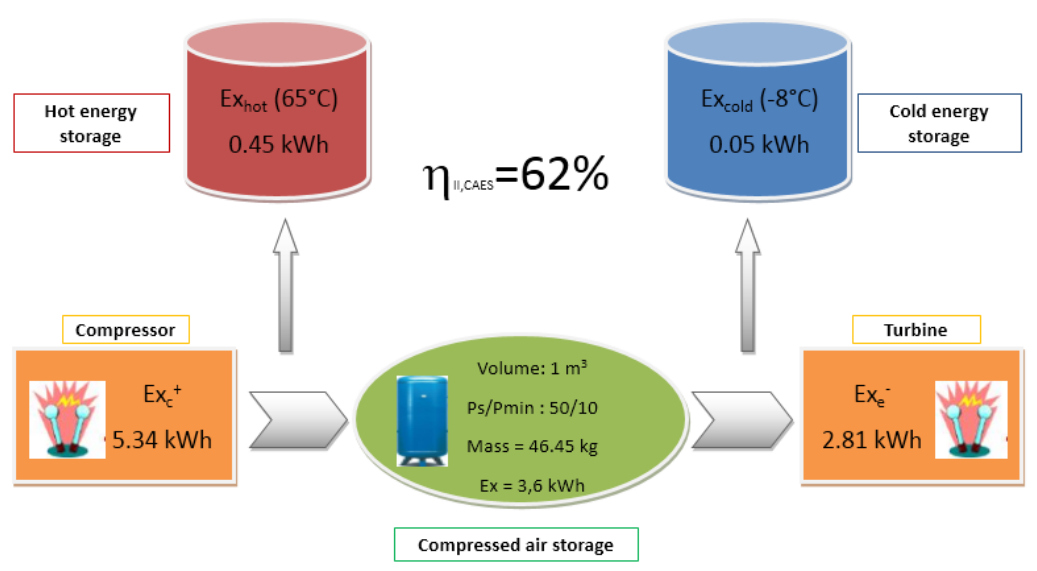

(b) Exergy results

Polygenerative system

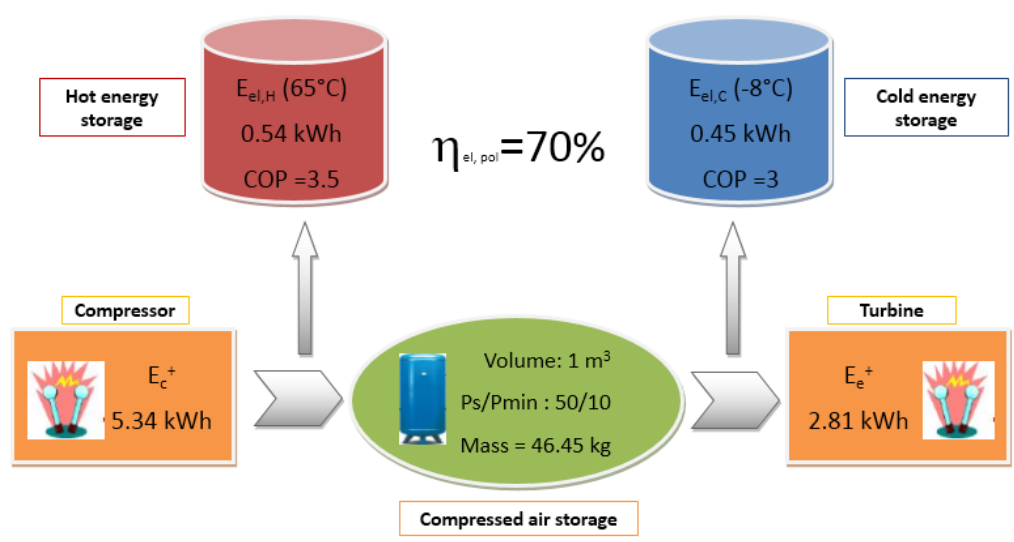

(c) Polygenerative system results

Fig. 2 Summary of the model simulation results. 


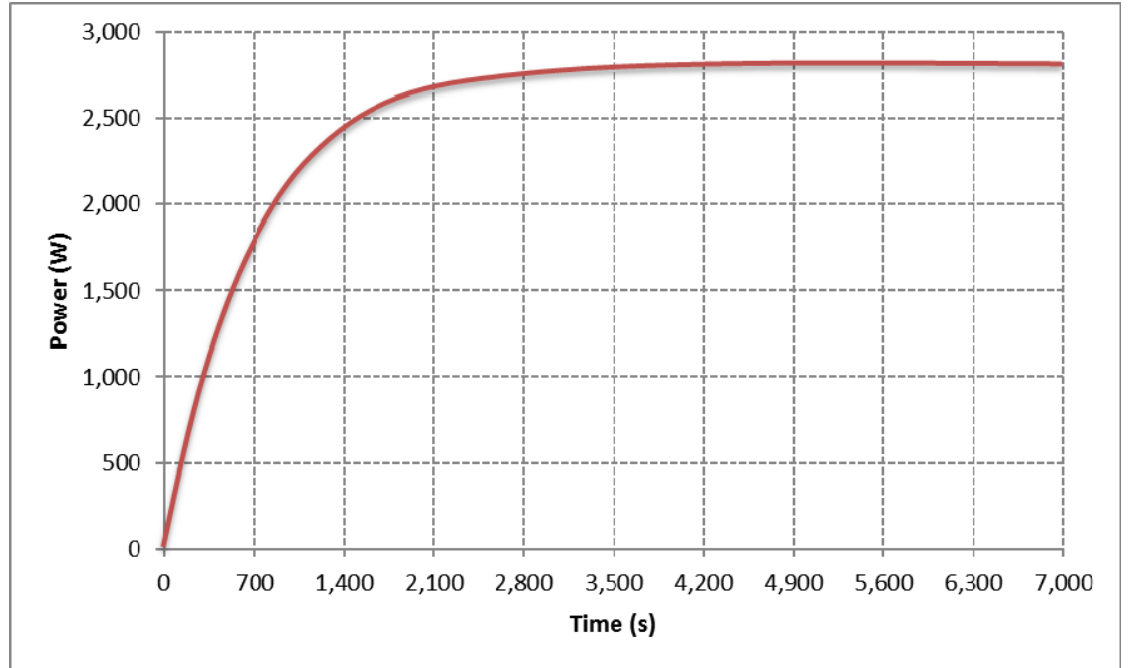

Fig. 3 Trend of electrical power during compression phase.

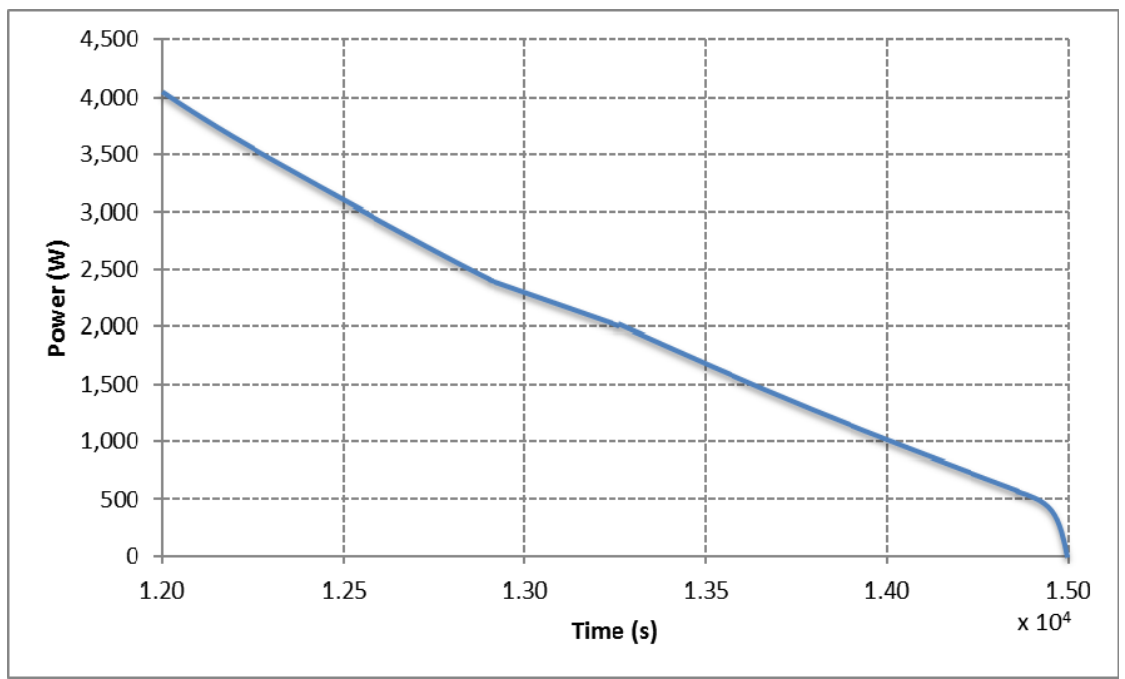

Fig. 4 Trend of electrical power during expansion phase.

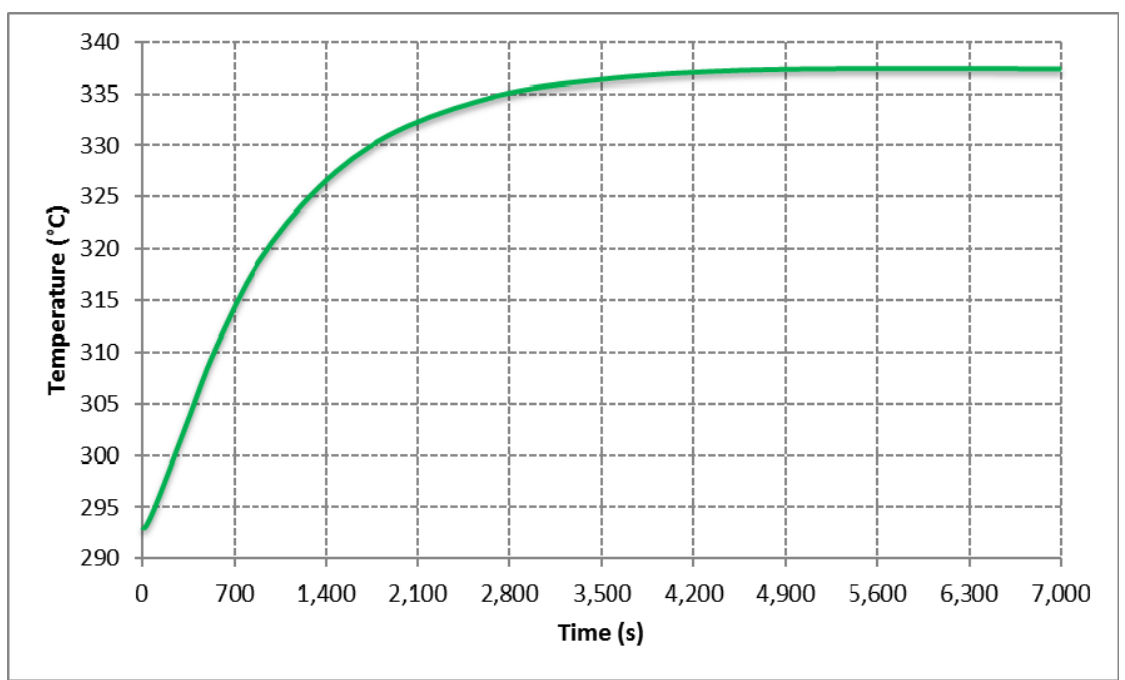

Fig. 5 Trend of temperature in the thermal storage. 


\section{Conclusions}

In this paper a new tri-generation system based on quasi isothermal compression in a compressed air energy storage is presented. Compared to other traditional CAES systems, the proposed CAES system has several advantages. First, the proposed system can simultaneously provide mechanical energy, heating and cooling energy. Second, discharged air of the turbine in the proposed system is not abandoned, instead it is reused completely as cooling power. Thermodynamic and energetic analysis of the proposed system have been carried out and the thermodynamic model was validated by comparing it with the Kim's model.

Some important conclusions can be drawn from the analysis of the system with the validated thermodynamic model. The results indicate that using discharged air as cooling power can improve the total energy efficiency of the CAES system by $20 \%$ in theory. Therefore, this system is very important and worthy of being considered for residential and where the environmental aspect is important.

\section{References}

[1] Tan, W. S., Hassan, M. Y., Majid, M. S., and Rahman, H. A. 2013. "Optimal Distributed Renewable Generation Planning: A Review of Different Approaches." Renewable and Sustainable Energy Reviews 18 (February): 626-45.

[2] Mahlia, T. M. I., Saktisahdan, T., Jannifar, A., Hasan, M., and Matseelar, H. 2014. "A Review of Available Methods and Development on Energy Storage; Technology Update." Renewable and Sustainable Energy Reviews 33 (May): 532-45.

[3] Akinyele, D. O., and Rayudu, R. K. 2014. "Review of Energy Storage Technologies for Sustainable Power Networks." Sustainable Energy Technologies and Assessments 8 (December): 74-91.

[4] Foley, A., and Lobera, I. D. 2013. "Impacts of Compressed Air Energy Storage Plant on an Electricity Market with a Large Renewable Energy Portfolio." Energy 57 (August): 85-94.

[5] Lund, H., Salgi, G., Elmegaard, B., and Andersen A. N. 2009. "Optimal Operation Strategies of Compressed Air Energy Storage (CAES) on Electricity Spot Markets with
Fluctuating Prices." Applied Thermal Engineering 29 (5-6): 799-806.

[6] Baqari, F. F, and Vahidi, B. 2013. "Small-Compressed Air Energy Storage System Integrated with Induction Generator for Metropolises: A Case Study." Renewable and Sustainable Energy Reviews 21 (May): 365-70.

[7] Kim, Y. M., and Favrat, D. 2010. "Energy and Exergy Analysis of a Micro-Compressed Air Energy Storage and Air Cycle Heating and Cooling System." Energy 35 (1): 213-20.

[8] Zhao, P., Dai, Y., and Wang, J. 2014. "Design and Thermodynamic Analysis of a Hybrid Energy Storage System Based on A-CAES and FESS for Wind Power Application.” Energy 70 (June): 674-84.

[9] Bagdanavicius, A., and Jenkins, N. 2014. "Exergy and Exergoeconomic Analysis of a Compressed Air Energy Storage Combined with a District Energy System." Energy Conversion and Management 77 (January): 432-40.

[10] Li Y., Wangb X., Li D., and Ding Y. 2012. "A Trigeneration System Based on Compressed Air and Thermal Energy Storage." Applied Energy 99 (November): 316-23.

[11] Grazzini, G., and Milazzo, A. 2008. "Thermodynamic Analysis of CAES/TES Systems for Renewable Energy Plants." Renewable Energy 33 (9): 1998-2006.

[12] Alami, A. H. 2015. "Experimental Assessment of Compressed Air Energy Storage (CAES) System and Buoyancy Work Energy Storage (BWES) as Cellular Wind Energy Storage Options." Journal of Energy Storage 1 (June): 38-43.

[13] Wang, S., Chen, G., Fang, M., and Wang, Q. 2006. "A New Compressed Air Energy Storage Refrigeration System." Energy Convers Manage 47 (18-19): 3408-16.

[14] Ibrahim, H., Younes, R., Ilinca, A., Dimitrova, M., and Perron, J. 2010. "Study and Design of a Hybrid Wind Diesel Compressed Air Energy Storage System for Remote Areas." Applied Energy 87 (5): 1749-62.

[15] Ibrahim, H., Younes, R., Basbous, T., Ilinca, A., and Dimitrova, M. 2011. "Optimization of Diesel Engine Performances for a Hybrid Wind Diesel System with Compressed Air Energy Storage." Energy 36 (5): 3079-91.

[16] Jannelli, E., Minutillo, M., Lubrano Lavadera, A., and Falcucci, G. 2014. “A Small Scale CAES (Compressed Air Energy Storage) System for Stand-Alone Renewable Energy Power Plant for a Radio Base Station: A Sizigi-Design Methodology." Energy 78 (December): 313-22.

[17] Liu, J. L., and Wang, J. H. 2015. "Thermodynamic Analysis of a Novel Tri-Generation System Based on Compressed Air Energy Storage and Pneumatic Motor." 
Energy 91 (November): 420-9.

[18] Hugenroth, J., Braun, J., Groll, E., and King, G. 2006. "Liquid-Flooded Ericsson Cycle Cooler: Part 1Thermodynamic Analysis." In Proceedings of the Inernational Refrigeration and Air Conditioning Conference, Paper 823.

[19] Hugenroth, J., Braun, J., Groll, E., and King, G. 2006. "Liquid-Flooded Ericsson Cycle Cooler: Part 2Experimental Results." In Proceedings of the Inernational Refrigeration and Air Conditioning Conference, Paper 824.

[20] Bell, I., Lemort, V., Groll, E., Braun, J. E., and King, G. 2012. "Liquid-Flooded Compression and Expansion in Scroll Machines-Part I: Model Development." International Journal of Refrigeration 35 (7): 1878-89.

[21] Bell, I., Lemort, V., Groll, E., Braun, J. E., and King, G.
2012. "Liquid-Flooded Compression and Expansion in Scroll Machines-Part II: Experimantal Testing and Model Validation." International Journal of Refrigeration 35 (7): 1890-900.

[22] Dinçer, İ., and Rosen, M. A. 2010. Thermal Energy Storage (TES) Methods, in Thermal Energy Storage: Systems and Applications. 2nd edition. Chichester: John Wiley \& Sons.

[23] Kim, Y. M., Lee, J. H., Kim, S. J., and Favrat, D. 2012. "Potential and Evolution of Compressed Air Energy Storage: Energy and Exergy Analysis." Entropy 14 (8): 1501-21.

[24] Kim, Y. M. 2012. "Novel Concepts of Compressed Air Energy Storage and Thermo-Electric Energy Storage." Ph.D. thesis, the Ecole Polytechnique Federale de Lausanne. 